\title{
Research on Key Technologies and Scenario Application of Emerging Business under the Energy Internet
}

\author{
Wang Yongli ${ }^{3}$, Zhao Zihao ${ }^{2}$, Huo Huijuan ${ }^{1}$, Zhang Danyang, ${ }^{3, *}$, Zhu Jinrong $^{3}$, Qi chengyuan ${ }^{3}$ \\ ${ }^{1}$ State Grid Economic Technological Research Institute Co., Ltd, Beijing, 102209, China \\ ${ }^{2}$ Economic and Technological Research Institute of State Grid Hebei Electric Power Co., Ltd, Shijiazhuang, 050022, China \\ ${ }^{3}$ North China Electric Power University, Beijing, 102206, China
}

\begin{abstract}
Under the energy Internet situation, the market-oriented competition of emerging power grid businesses is increasingly intensified. The traditional single-type information construction system and model cannot adapt to the market. Therefore, this paper proposes a shared service architecture technology for China and Taiwan. This article introduces the goals and architectural ideas of the China-Taiwan shared service architecture and proposes a five-step method to sort out shared service centers. When the enterprise implements the China-Taiwan shared service center architecture, it proposes the implementation strategy of minimizing closed-loop principles and staged iterations, which are shown through research and application. , China-Taiwan shared service architecture can support grid companies to quickly respond to the needs of emerging power business markets, and play an IT support rote-for grid companies in the transformation process.
\end{abstract}

\section{Introduction}

In 2019, the "Two Sessions" of the State Grid Corporation of China will comprehensively promote the construction of "three types and two networks" and accelerate the strategic deployment of building a worldclass energy internet enterprise with global competitiveness. This is a concrete practice of the network power strategy and is the implementation of the central deployment and development important measures taken by central enterprises to take the lead are inevitable requirements for adapting to internal and external situations and challenges. In this context, with the continuous development of the reform of the electricity sales side market in my country, the marketoriented competition of electricity sales is increasingly intensified, and the traditional electricity market is facing more and more opportunities and challenges[1-4]. How the traditional IT architecture of power grid enterprises adapts to the strategic transformation under the new situation of market-oriented competition has become a key issue that must be solved in the informatization construction of power grid enterprises [5]. In the face of the acceleration of domestic electric power market reform, power grid enterprises face in the field of traditional with electric diversified competition in the market, such as charging pile, sell electricity, new energy vehicles, photo voltaic (PV), energy storage, and another emerging market, market competition means market fast-changing, the traditional IT construction patterns, on average, the project delivery cycle (a domestic power supply bureau from June 2014 to February 2020 during the 143 traditional information

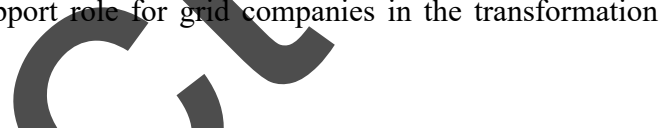

statistics from project to project system officially launched the average length of as shown in table 1) for six months in a year. On the whole, due to the independent development of each business application system, the lack of unified standards and specifications, the uneven technical level, the level of user experience, the lack of operational thinking, only function realization, no continuous optimization, repeated development and maintenance of common functions, resulting in the waste of resources, lack of effective precipitation. Moreover, there is a lack of overall planning at the business level, and business implementation is heavily dependent on front-end application systems, and effective collaboration between business modules across application systems cannot be achieved.

\section{Research on key technologies}

As my country's power market and system reforms enter the deep water area, the market-oriented competition in power emerging businesses has intensified. Responding to the rapidly changing market environment requires flexible and powerful information technology support. The construction of a China-Taiwan shared service center is an important measure for the development of new businesses in the power grid under market competition.

\subsection{Architecture goals}

The China-Taiwan shared service architecture achieves the following goals:

* Corresponding author: HBBDndyz@163.com 
1) Technical architecture transformation: Through the construction of a shared service center, the common function sharing of front-end business application systems are realized, avoiding repetitive development and maintenance work, and the combination of shared services is conducive to rapid response to market demand.

2) Organizational structure transformation: Cultivating a team of compound talents, and improving the technical capabilities of personnel and teams in the information department.

3) Business operation model innovation: Continuous access to new services, shared services continue to evolve into more robust and powerful services, and constantly adapt to various business lines, which can respond to the future faster innovation needs and lowercost business exploration.

4) Data association: The data of each business is deposited in the same set of shared services, which can accumulate data continuously, and finally exert the power of big data [9].

Eventually, it will form a comprehensive energy solution centered on shared services to quickly meet user needs, provide front-end users with a "one-stop, comprehensive, and customized" comprehensive energy solution, leading the two-way transformation of enterprise technology and business.

\subsection{Architecture scheme}

As showed in Figure 1, the front-end, middle-end, and back-end architecture schemes are adopted. The frontend is flexible and adaptable to market changes. The middle-end provides enterprise core business capabilities and technical capabilities, and the back-end provides strong resources and middleware support [10

Front desk: The thinner layer of business processing logic is mainly to interact with users, and frequently changing business capabilities are placed in the foreground to collect user information and facilitate data processing.

Middle office: A thicker layer of business capabilities, mainly the relatively fixed business capabilities of the company with core competitiveness; provide unified business and technical service capabilities to the front desk. Taking enterprise-level shared services as the core, gradually accumulate common business and data service capabilities, and build enterprise middle stations, including business middle stations and data middle stations.

Background: Provide flexible basic resources, including cloud computing resources, cloud storage resources, cloud network resources, and other basic resources; at the same time, it also provides components that support the operation of a large number of middlestation service capabilities, including distributed services, message queues, service scheduling, cloud security, and other components.

Monitoring: Provide service operation monitoring function, and realize the automatic expansion of service instances, service fuse, downgrade, etc. through service automatic configuration.

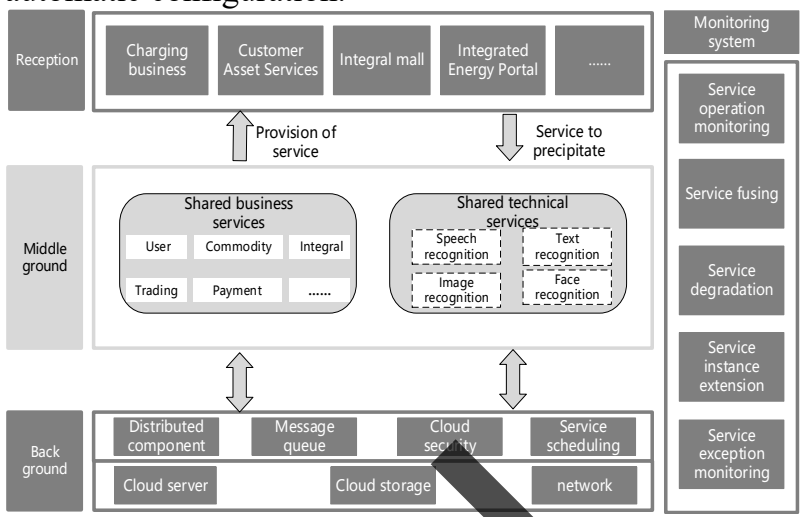

Fig. 1. Central and Taiwan Shared-Service Architecture

\subsection{Methodology}

In the China-Taiwan shared service architecture, the back-end part currently has mature cloud platform solutions. As a traditional power company, there is no need to work in this field, and the existing mature cloud platform solutions are directly used to provide basic resources and capability components; Because it is only a thin layer of user interaction, the technical threshold is low, the difficulty is low, and it does not have core values; the China-Taiwan Shared Service Center is the top priority of enterprise transformation, and the quality of China-Taiwan construction is directly related to the success or failure of enterprise transformation. How to sort out and identify the potential shared services of enterprises, this article provides a five-step method for rting out shared services:

1) Service center modeling: The process of dividing the business boundary and describing the business capabilities of the business involved in the enterprise. The main methodologies at this stage include Business Process Analysis (BPA) and Domain-Driven Design (DDD), this stage will produce a "high-level architecture of shared service centers", that is, which shared service modules the enterprise should have.

2) Service architecture: After the high-level architecture of the shared service is produced, the service is then identified according to the business process of the business requirement analysis, to perform serviceoriented architecture modeling. The main methodology at this stage is the DDD tactical design, which produces a "shared service center catalog", that is, what services each center should have.

3) Service design: According to the service catalog, refer to the principles of service design and implementation to form a service interface.

4) Service realization: According to the service interface, service design and service realization are finally formed.

5) Service governance and evolution: After the service is deployed online, the service needs to be governed. At the same time, the service is continuously optimized and evolved based on service governance and business needs. 
The first two steps of the five-step method directly affect the quality of the construction of shared services in China and Taiwan, and are undoubtedly the key to sorting out shared services. The service center modeling and service architecture design based on business process analysis methods are shown in Figure 2.

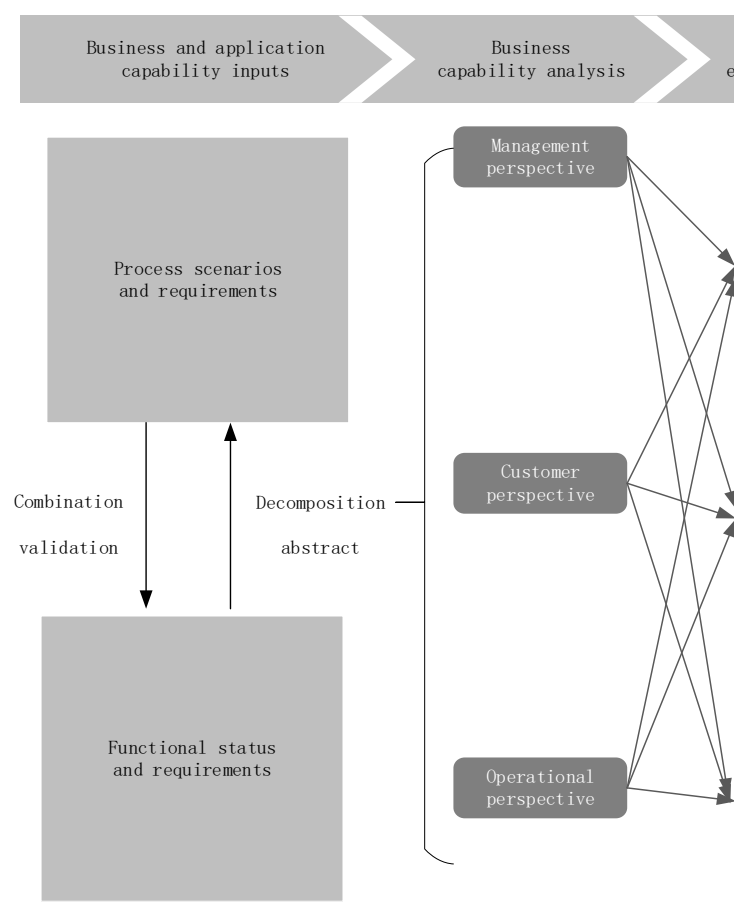

Fig. 2. Sharing Service Combing Method

Enterprise capabilities are embodied in business processes, and most of the business processes are solidified in information systems. Through the analy of business process scenarios and system functions, th three key elements of users, actions, and objects are disassembled from the perspectives of management, customers, and operations. The combination of is the enterprise's atomic business capabilities, and then through the analysis of the frequency and business coverage of the enterprise's atomic capabilities, the enterprise's shared service centers and the shared services under each service ce

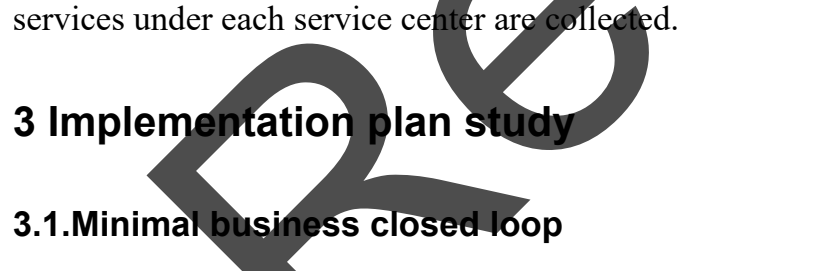

The purpose of the architecture of the shared service center is to reduce the complexity of the system through business splitting; to provide reusability through service sharing, and to achieve business support agility through servitization. The so-called "minimal business closedloop principle" refers to the implementation of the shared service center, with the smallest business closedloop as the unit to complete the design of the shared service center. In the early stage, the team will be gradually professionalized through a small cost and gradually professionalized. The continuous precipitation in the development process ensures the smooth implementation of the shared service center. Based on the characteristics of market-oriented competitive business, and according to the current development of power emerging businesses, user centers, commodity
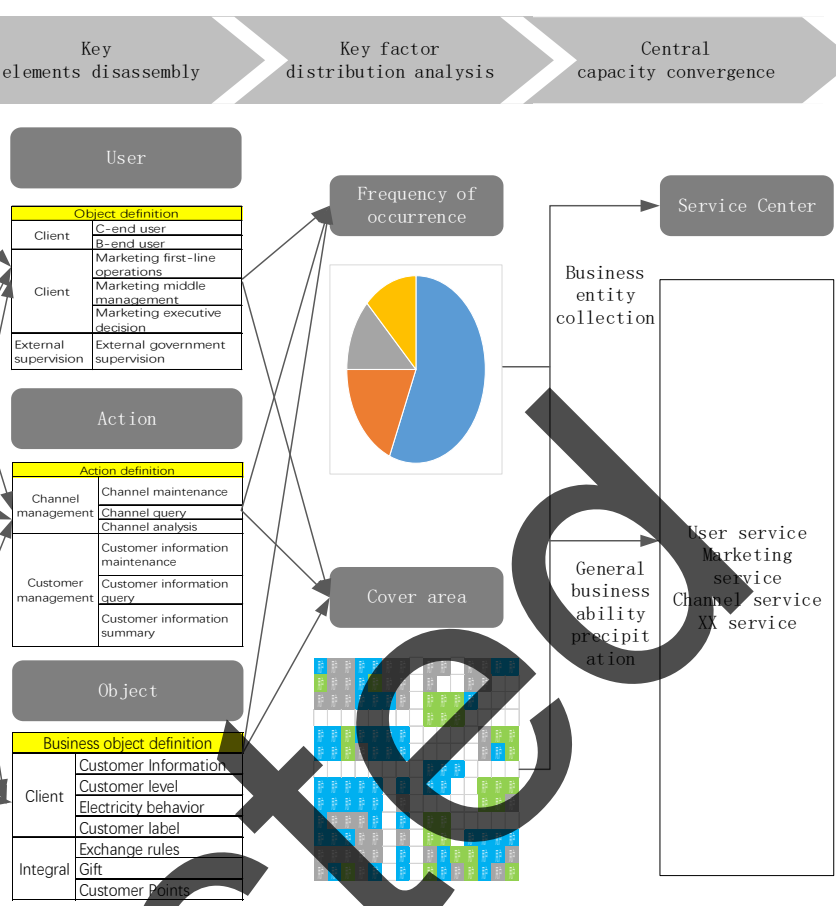

centers, transaction centers, and payment centers have been able to meet the minimum closed-loop requirements of the business. Each center is the core to build a service system architecture and build a minimized closed-loop business value chain.

\subsection{Phased iteration}

The construction of the sharing center is essentially a process of building a microservice architecture, not only a technological change but also the result of continuous business evolution. A series of problems that will be faced during and after the construction of the microservice architecture requires a professional team and platform to ensure the successful implementation of the microservice architecture. Building a microservice system architecture does not depend on a project to establish it. It requires continuous precipitation of service capabilities in the business development process. When the business capabilities are precipitated to a stage, the microservice architecture can truly feel the business development of the enterprise. Therefore, in the specific implementation of the value process, it is necessary to follow the principle of phase iteration and gradual implementation of the long-term value. The principle of phase iteration is from the perspective of risk reduction and implementation difficulty. Shared service architecture is originally an agile practice. It is recommended that the "small steps and fast running" approach is gradually advanced, rather than being overthrown vigorously.

Given the implementation of the China-Taiwan shared service architecture in the process of developing 
new businesses in the traditional power grid, the following path is recommended.

The first stage: Build a preliminary framework for the middle and back office, complete the construction of user, commodity, payment, and transaction centers, and support minimized closed-loop business.

The second stage: Continue to improve ChinaTaiwan shared business services and gradually cover all emerging businesses.

The third stage: Build a shared technology center to realize technology-driven business.

\section{Organizational Guarantee Mechanism}

At present, the functions of the information center department of most power grid enterprises are still at the level of "business support", which is an organization that provides IT system support for the business departments of the enterprise. Many things are essentially transactional work, and it is difficult for employees to continuously accumulate and precipitate their business or professional capabilities. The productivity and innovation atmosphere of the entire information department will also be greatly affected. The establishment of a shared service system by enterprises will completely change the current model of single system construction. New projects will be based on the construction of a shared service system. The construction period and resource input of the project will bring a great efficiency improvement compared with the previous on The above requires that the staff of the information center department should be reorganized according to the way of the service center so that the employees can continue to develop in the business areas they are good at and interested in. The business understanding and professional skills of the employees follow the business provided by the corresponding service eenter. The ability is gradually improved and improved simultaneously. Finally, through the construction of the shared service system and the adjustment of the organizational formation, the enthusiasm and innovation consciousness of employees are effectively improved, and the productivity and business response efficiency of the entire department are improved.

\section{Conclusion}

This paper analyzes the current situation of power grid enterprise information system construction, combined with the current problems encountered in the development of new power grid services, proposes a China-Taiwan shared service architecture and analyzes the value of the China-Taiwan shared service architecture for the development of emerging businesses of power grid companies. The platform shared service architecture and implementation plan provide useful explorations for the transformation of power grid companies. When implementing the central platform architecture, as it is a subversion of the traditional system construction model, the organizational guarantee is the top priority for the successful implementation of the central platform architecture. With continuous operation, only China and Taiwan can continue to play their value and further develop the emerging business of the power grid and open up new paths and directions.

\section{Acknowledgments}

This paper was funded by the State Grid Corporation Science and Technology Project: Research on Investment Value Evaluation and Investment Optimization Technology of Power Grid Emerging Business(1300-202056133A-0-0-00).

\section{References}

1. Feng G.P., Xie W.Y., Ji X.H. (2017) Research on the development of China Southern Power Grid's big data. J. Southern Energy Construction, 4: 13$17+27$.

2. Huang Y. (2016) The history and enlightenment analysis of Singapore's power system reform. J. Southern Energy Construction, 3(1): 36-40.

3. Liu F., Ju W. (2018) Research on the management strategy of electric power enterprises based on the reform of the electricity sales side. J. Science and Technology Information, 16(32): 134-135.

4. Qi S.H. (2012) Talking about the marketing strategy and the importance of electric power company. J. Enterprise Technology Development, 31(31): 97$98+104$.

5. Gu M.S., Xie W.Y., Cui Y. (2016) Research on IT architecture of de-systematic power grid enterprises. J. Southern Energy Construction, 3(2): 118-121+126.

6. Zhong H. (2017) The Transformation of Enterprise IT Architecture-Alibaba's Strategic Thinking and Framework Practice. M. Machinery Industry Press, Beijing.

7. Caixin.com. 2018. The annual transaction volume of Sinopec's e-commerce platform exceeds RMB 100 billion. http: //companies. caixin. com/2018-0419/101236327. html.

8. Si S.Y. (2019) China-Taiwan architecture helps the transformation and upgrading of the production execution system of the aviation manufacturing industry. J. Information Technology and Informatization, (4): 22-24. 